\title{
Effects of distance and transport method on intervention and mortality in aneurysmal subarachnoid hemorrhage
}

\author{
Jonathan Weyhenmeyer, MD, ${ }^{1}$ Cristian F. Guandique, BA, ${ }^{2}$ Adam Leibold, ScM, ${ }^{2}$ \\ Stephen Lehnert, MD, ${ }^{2}$ Jonathan Parish, MD, ${ }^{3}$ Woody Han, MD, ${ }^{2}$ Chad Tuchek, MD, ${ }^{2}$ \\ Janit Pandya, BS, ${ }^{2}$ Thomas Leipzig, MD, ${ }^{1}$ Troy Payner, MD, ${ }^{1}$ Andrew DeNardo, MD, ${ }^{1}$ \\ John Scott, MD, ${ }^{1}$ and Aaron A. Cohen-Gadol, MD ${ }^{1}$
}

${ }^{1}$ Goodman Campbell Brain and Spine and Department of Neurosurgery, Indiana University, Indianapolis; ${ }^{2}$ ndiana University School of Medicine, Indianapolis, Indiana; and ${ }^{3}$ Carolina's Medical Center Department of Neurosurgery, Charlotte, North Carolina

OBJECTIVE Most patients suffering from aneurysmal subarachnoid hemorrhage (aSAH) initially present to a hospital that lacks a neurosurgical unit. These patients require interhospital transfer (IHT) to tertiary facilities capable of multidisciplinary neurosurgical intervention. Yet, little is known about the effects of IHT on the outcomes of patients suffering from aSAH. In this study, the authors examined the effects of IHT and transport method on the timing of treatment, rebleed rates, and overall outcomes of patients who have experienced aSAH.

METHODS A retrospective review of medical records identified all consecutive patients who presented with aSAH at an outside hospital and subsequently underwent IHT to a tertiary aneurysm care center and patients who initially presented directly to a tertiary aneurysm care facility between 2008 and 2015. Demographic, operative, radiological, hospital of initial evaluation, transfer method, and outcome data were retrospectively collected.

RESULTS The authors identified 763 consecutive patients who were evaluated for aSAH at a tertiary aneurysm care facility either directly or following IHT. For patients who underwent IHT and after accounting for these patients' clinical variability and dichotomizing the patients into groups transferred less than 20 miles and more than 20 miles, the authors noted a significant increase in mortality rates: $7 \%$ (<20 miles) and 18.8\% (> 20 miles) $(p=0.004)$. The increased mortality rate was partially explained by an increased rate of initial presentation to an accredited stroke center in patients undergoing IHT of less than 20 miles $(p=0.000)$. The method of transport (ground or air ambulance) was found to have significant effect on the patients' outcomes as measured by the Glasgow Outcome Scale score $(p=0.021)$; patients who underwent ground transport demonstrated a higher likelihood of discharge to home $(p=0.004)$. The increased severity of presentation in the patient cohort undergoing IHT by air as defined by the Glasgow Coma Scale score, a need for an external ventricular drain, Hunt and Hess grade, and intubation status at presentation did not result in increased mortality when compared with the ground cohort $(p=0.074)$. In addition, there was an 8-hour increase in duration of time from admission to treatment for the air cohort as compared with the ground cohort $(p=0.054)$, indicating a potential for further improvement in the overall outcome of this patient group.

CONCLUSIONS Aneurysmal SAH remains a challenging neurosurgical disease process requiring highly coordinated care in tertiary referral centers. In this study, the overall distance traveled and the transport method affected patient outcomes. The time from admission to treatment should continue to improve. Further analysis of IHT with a focus on patient monitoring and treatment during transport is warranted.

https://thejns.org/doi/abs/10.3171/2016.9.JNS16668

KEY WORDS aneurysmal subarachnoid hemorrhage; interhospital transfer; outcomes; vascular disorders

ABBREVIATIONS aSAH = aneurysmal subarachnoid hemorrhage; EVD = external ventricular drain; GCS = Glasgow Coma Scale; GOS = Glasgow Outcome Scale; IHT = interhospital transfer; IU = Indiana University; LTAC = long-term acute care; OSH = outside hospital; SNF = skilled nursing facility; WFNS = World Federation of Neurosurgical Societies.

SUBMITTED March 16, 2016. ACCEPTED September 28, 2016.

INCLUDE WHEN CITING Published online February 10, 2017; DOI: 10.3171/2016.9.JNS16668. 
A NEURYSMAL subarachnoid hemorrhage (aSAH) represents $5 \%$ of strokes; however, it accounts for $27 \%$ of all potential human-years lost before age 65 years due to stroke. ${ }^{10,26}$ The increase in premature death arises from the increased prevalence of aSAH in younger patients and its high case-fatality rate. ${ }^{10,14}$ Moreover, while the incidence of all-cause strokes has been steadily declining due to improvements in modifiable risk factors, a comparable decrease has not been seen in the incidence of aSAH. ${ }^{3,4}$ As such, aSAH remains a significant cause of morbidity and mortality. . $^{3,10,23,26}$

The most common causes of poor outcome in aSAH patients are the initial bleed, rebleeding, and vasospasm. ${ }^{2,5,21,24}$ Rebleeding is most likely to occur within the first 6 hours following initial aSAH. ${ }^{4,8,9}$ Patients who experience a rebleeding episode are more likely to die, with a reported $50 \%-70 \%$ mortality rate..$^{8,15,24}$ Rebleeding is prevented through successful microsurgical clipping or endovascular therapy. ${ }^{1}$ The timing of intervention in aSAH has been a focal point of aneurysm research, ${ }^{6}$ with studies showing no significant difference in the morbidity and mortality when comparing early (0-3 days) and late (11-14 days) intervention. ${ }^{11,12}$ Further comparison of early intervention (within 3 days of aSAH) and ultra-early intervention (within 24 hours) showed no improvement in the rate of rebleeding. This finding may be explained by the time frame for ultra-early rebleeding that is less than 6 hours. ${ }^{13}$ Indeed, studies examining emergency intervention (within 3 hours of hospital admission) have shown an improvement in the rebleed rate and overall patient outcomes. ${ }^{19}$

Many patients experiencing aSAH initially present to a hospital that lacks a neurosurgical unit. These patients require interhospital transfer (IHT) to tertiary facilities capable of a higher level of aneurysm care and coordination of neurosurgical intervention. ${ }^{16}$ Rebleeding has been found to occur during transfer and is considered a significant cause of patient deterioration. ${ }^{20,22}$ While some studies have found IHT and transfer distance to have a negative effect on patient outcomes, large epidemiological studies have found no difference in patient outcome due to transfer. ${ }^{16-18}$ The decision as to when and how a patient should be transported remains open to interpretation. One study at a high-volume tertiary care center found that $57.5 \%$ of patients undergoing IHT for neurosurgical care underwent no intervention, and more than $5 \%$ were stepped down to a lower level of care on admission. ${ }^{7}$ The decision to transport via ground or air ambulance is multifactorial. Other studies have shown limited improvement in treatment times and patient outcomes for neurosurgical transfers. ${ }^{25,28}$ Furthermore, the expectations may not be clearly discussed among the accepting physician, referring physician, and family with respect to the reasoning behind IHT. $^{27}$

Indiana University (IU) Health Methodist Hospital located in Indianapolis functions as the primary tertiary care facility for aneurysm care in the state of Indiana, receiving aSAH patients from across the state and surrounding region. This study examines the effects of IHT and transport method on the timing of treatment, rebleed rates, and overall outcomes of patients treated for aSAH.

\section{Methods \\ Patient Population}

We have prospectively maintained a neurovascular database of all patients treated at IU Health Methodist Hospital who have experienced cerebral aneurysm(s) since 1976. We performed a retrospective single-institution study of all patients who initially presented with aSAH to Methodist Hospital or an outside hospital (OSH) and subsequently underwent IHT to Methodist Hospital during an 8-year period between January 2008 and December 2015. All patients who were initially misclassified as experiencing aSAH due to trauma or mycotic aneurysm were excluded. Patients who underwent multiple IHTs or initial treatment for their aneurysm at an outside facility were also not analyzed.

\section{Data Collection}

We collected demographic, clinical (including radiological, hospital of initial evaluation, transfer method, i.e., air or ground ambulance), and outcome data. The hospital of initial evaluation and the transfer method were collected from outside records. Transfer distance was dichotomized as less than 20 miles and more than 20 miles. This methodology is justified since a distance of less than 20 miles from Methodist Hospital fell within an area where a patient can be quickly transported to Methodist Hospital for high-level neurosurgical care. The utility of this designation is multifactorial as hospitals within the 20-mile radius are more likely to have transfer agreements in place, allowing for quick communication between accepting and referring providers and frequently used transfer protocols.

Transfer distance was calculated differently depending on the method of transport. Air transport was calculated based on a linear distance from the address of the outside hospital to Methodist Hospital. Ground transport distance was calculated using Google Maps software (maps.google. com), with the fastest route assumed to be the route taken. The time of transport was not included in this study due to inadequate record keeping within transfer notes regarding the departing, arrival, and total transport times.

The onset of aSAH was determined from OSH, emergency department, and admission notes. Patients without a definable onset time and patients with onset longer than 1 week prior to admission were excluded. Patients' statuses according to the Hunt and Hess and World Federation of Neurosurgical Societies (WFNS) grades at admission were obtained from admission documents. Fisher grade was determined based on radiology reports. Timing of intervention (e.g., surgical clipping or coiling) was determined from operative time logs. Outside records, admission notes, progress notes, transport documents, and procedural reports were reviewed to determine the patients' Glasgow Coma Scale (GCS) score and intubation/external ventricular drain (EVD) status at the OSH and on admission to Methodist Hospital. Additional data were collected for patients who were intubated or had an EVD placed after admission, prior to definitive intervention. The designations of the OSHs as stroke centers were determined based on the accreditation provided by the Joint Commission on Accreditation of Healthcare organizations. Only 
those hospitals that had completed stroke center verification were considered to be true stroke centers.

\section{Outcome Measures}

Rebleeding was determined to occur based on the onset of further neurological deterioration and concurrent demonstration of an increased or new focus of hemorrhage on subsequent noncontrast $\mathrm{CT}$ imaging. Treatment time intervals were calculated for time from aSAH to intervention and also the interval from admission to Methodist Hospital until intervention. The Glasgow Outcome Scale (GOS) score and discharge destination (home, rehabilitation facility, skilled nursing facility [SNF], long-term acute care [LTAC] facility, and death [in-hospital death and discharge to hospice]) were used to assess patient outcomes at discharge. Long-term follow-up data were not reliably available, with a significant portion of the patient population dropping out at 6 months. Thus, the follow-up for this study was limited to discharge GOS score and discharge location. Death was determined from hospital records (death notices and discharge to hospice care).

\section{Statistical Analysis}

Data analysis was performed using SPSS (version 19.0, IBM) and Microsoft Excel (version 2010). Data are presented as means $\pm \mathrm{SD}$. Statistical significance was set at $\mathrm{p}<0.05$.

We performed independent t-tests to identify any significant differences between age, aneurysm size, admission to treatment time, and time of aSAH onset to treatment among the groups transferred from different distances. Chi-square analysis was used to identify any statistically significant differences among the frequency data; such variables included the risk of hypertension and smoking/ alcohol use, treatment type, the location of the aneurysm, rebleed frequency, transfer from stroke center, mortality, cause of death, the use of antifibrinolytic therapy, and if an intervention was rendered. In select instances, Fisher's exact test was used when sample sizes were too small, such as the number of patient transfers from stroke centers and rebleed rates.

In addition, we performed Mann-Whitney U-tests on the nonparametric ordinal data, including admission Hunt and Hess score, WFNS grade, Fisher grade, and GOS score at discharge. All analyses were repeated among the patients who underwent the different transfer methods. We ran an ANOVA to test for any significant differences in age, aneurysm size, admission to treatment time, time of aSAH onset to treatment, and mortality between those who were transported directly to Methodist Hospital and the different IHT groups. A logistic regression was performed to predict the probability of mortality using the following selected variables: history of hypertension, aneurysm size, admission Hunt and Hess score, WFNS grade, the need for EVD at admission, and GCS score at the OSH.

\section{Results}

Based on our analysis, 763 consecutive patients who experienced aSAH were identified as being evaluated for
aSAH at Methodist Hospital. The following patients were excluded according to the previously mentioned exclusion criteria: unknown time of aSAH onset $(n=96)$, patients misclassified as experiencing aSAH $(n=18)$ or harboring a pseudoaneurysm $(n=1)$, patients who underwent multiple IHTs $(n=18)$, and patients who did not have adequate medical records available $(n=26)$. Therefore, 604 patients were included in the final analysis.

\section{Patients Grouped by Direct Presentation or Interhospital Transport}

An initial comparison was made between the cohort of patients who presented directly to a tertiary aneurysm facility ( $\mathrm{n}=68$; mean age $55.5 \pm 13.2$ years) and those transferred from a referring outside hospital $(n=536$; mean age $52.3 \pm 11.5$ years). The demographics for the 2 groups are displayed in Table 1 . There were no statistically significant differences in age, sex, preponderance of hypertension, smoking status, alcohol usage, aneurysm location, or method of treatment (clip or coil).

The metrics for severity of condition on presentation were shown to be largely similar, with a few notable exceptions. The WFNS and Fisher grades on admission were not statistically different between the 2 groups. The Hunt and Hess grade on admission was slightly worse for the group undergoing IHT, but this comparison failed to reach statistical significance $(\mathrm{p}=0.05)$. There was no statistically significant difference in the rebleed rate across the 2 groups, but the rebleed rate was increased in the group undergoing IHT. While the GCS score on arrival was slightly worse for the transferred group, it also did not reach statistical significance. Moreover, the rate of EVD placement was similar across the groups. The outcome statistics demonstrated no significant differences between the 2 groups for GOS score and discharge disposition to home, rehabilitation facility, SNF/LTAC, and death.

\section{Patients Grouped by Transfer Distance}

The IHT patients were dichotomized into 2 groups of patients transferred less than 20 miles $(n=100$; mean age $56.6 \pm 12.9$ years) and patients transferred more than 20 miles $(n=436$; mean age $55.4 \pm 13.2$ years). Additional demographics, shown in Table 2, for the 2 groups were not statistically different in terms of age, sex, history of smoking, alcohol use, and preponderance of hypertension. Other variables, including aneurysm location (posterior vs anterior circulation) and aneurysm size, were also similar.

The patients' grades on admission to Methodist Hospital were similar, with no comparisons reaching statistical significance based on Hunt and Hess, WFNS, and Fisher grades. While the patient group transferred less than 20 miles experienced a higher rate of preprocedural rebleeding (6\% vs 3.2\%), this failed to reach statistical significance. There were no statistically significant differences between the number of hours from the time of admission to intervention and the onset of aSAH to intervention between the 2 groups.

Analysis of the initial hospital of presentation showed a significant difference in the number of patients initially 
TABLE 1. Clinical features of the patients who were directly transferred to Methodist Hospital versus those who underwent $\mathrm{IHT}$

\begin{tabular}{|c|c|c|c|}
\hline Variable & $\begin{array}{l}\text { No Transfer } \\
(\mathrm{n}=68)\end{array}$ & $\begin{array}{l}\text { Transfer } \\
(n=536)\end{array}$ & $\begin{array}{c}p \\
\text { Value }\end{array}$ \\
\hline Mean age (yrs) & $55.5 \pm 13.2$ & $52.3 \pm 11.5$ & 0.053 \\
\hline Female sex & $52(76.4 \%)$ & $376(70 \%)$ & 0.280 \\
\hline HTN & $35(51 \%)$ & $284(53 \%)$ & 0.814 \\
\hline Smoker & $41(60 \%)$ & $324(60 \%)$ & 0.981 \\
\hline Alcohol use & $22(32 \%)$ & $178(33 \%)$ & 0.888 \\
\hline \multicolumn{4}{|l|}{ Treatment* } \\
\hline Clip & $31(46 \%)$ & $244(46 \%)$ & 0.930 \\
\hline Coil & $32(47 \%)$ & $241(45 \%)$ & 0.991 \\
\hline No treatment & $4(6 \%)$ & $44(8 \%)$ & 1.0 \\
\hline Anterior circulation & $62(91 \%)$ & $441(82 \%)$ & 0.173 \\
\hline Mean aneurysm size (mm) & $6.6 \pm 3.6$ & $7.3 \pm 4.8$ & 0.134 \\
\hline Mean Hunt \& Hess grade & $2.3 \pm 1.3$ & $2.6 \pm 1.6$ & 0.050 \\
\hline Mean WFNS grade & $2.26 \pm 1.5$ & $2.6 \pm 1.6$ & 0.144 \\
\hline Mean Fisher grade & $3.3 \pm 0.8$ & $3.4 \pm 0.7$ & 0.316 \\
\hline Mean GOS score at discharge & $3.34 \pm 1.3$ & $3.2 \pm 1.2$ & 0.260 \\
\hline Intubated prior to arrival to IU & $7(10 \%)$ & $167(31 \%)$ & 0.000 \\
\hline Intubated after arrival to IU & $13(19 \%)$ & $27(5 \%)$ & 0.000 \\
\hline EVD on arrival to IU & $22(32.4 \%)$ & $158(29.5 \%)$ & 0.625 \\
\hline Mean GCS score on arrival to IU & $12.1 \pm 4.3$ & $11.3 \pm 4.4$ & 0.152 \\
\hline Stroke center & $68(100 \%)$ & $212(40 \%)$ & 0.000 \\
\hline Antifibrinolytic & $15(22 \%)$ & $112(21 \%)$ & 0.824 \\
\hline $\begin{array}{l}\text { Mean admission to treatment } \\
\text { time (hrs) }\end{array}$ & $22.3 \pm 20.2$ & $26.2 \pm 42.9$ & 0.382 \\
\hline Mean SAH to treatment time (hrs) & $29.7 \pm 23.9$ & $39.1 \pm 52.9$ & 0.160 \\
\hline Rebleeding & $1(1.5 \%)$ & $20(3.7 \%)$ & 0.496 \\
\hline \multicolumn{4}{|l|}{ Discharge disposition } \\
\hline Rehabilitation & $24(35 \%)$ & $236(44 \%)$ & 0.600 \\
\hline SNF/LTAC & $3(4.4 \%)$ & $23(4.3 \%)$ & 0.100 \\
\hline Death & $9(13 \%)$ & $88(16 \%)$ & 0.930 \\
\hline Home & $32(47 \%)$ & $189(35 \%)$ & 0.307 \\
\hline
\end{tabular}

HTN = hypertension .

Mean values are presented as the mean $\pm \mathrm{SD}$.

* One patient in the no-transfer group and 7 patients in the transfer group underwent both endovascular coiling and surgical clipping.

admitted to a stroke center: $70 \%$ for less than 20 miles and $32.6 \%$ for greater than 20 miles $(\mathrm{p}=0.000)$. There was also a significant difference in the overall mortality rates $(\mathrm{p}=0.004)$ but not in the morbidity rates of those who survived when taking into account discharge disposition to home ( $p=0.323)$, SNF/LTAC $(p=0.837)$, or rehabilitation facility $(p=0.261)$. Of note, there was a statistically significant difference in the mortality rate for patients with hypertension ( $2 \%$ for $<20$ miles and $12.2 \%$ for $>20$ miles $[\mathrm{p}=0.003]$ ), indicating that hypertension had a significant effect on mortality for patients undergoing IHT for longer distances.

Analysis of OSH placement of EVDs, OSH intubations, and OSH GCS assessments did not reach significance for these patient populations, again emphasizing the
TABLE 2. Clinical features of the patients who underwent IHT of less than versus more than 20 miles

\begin{tabular}{lccc}
\hline \multicolumn{1}{c}{ Variable } & $\begin{array}{c}<20 \text { Miles } \\
\text { IHT }(\mathrm{n}=100)\end{array}$ & $\begin{array}{c}>20 \text { Miles } \\
(\mathrm{n}=436)\end{array}$ & $\begin{array}{c}\mathrm{p} \\
\text { Value }\end{array}$ \\
\hline Mean age (yrs) & $56.6 \pm 12.9$ & $55.4 \pm 13.2$ & 0.433 \\
\hline Female sex & $73(73 \%)$ & $303(69.5 \%)$ & 0.490 \\
\hline HTN & $59(59 \%)$ & $225(51.6 \%)$ & 0.355 \\
\hline HTN \& mortality & $2(2 \%)$ & $53(12.2 \%)$ & 0.003 \\
\hline Smoker & $59(59 \%)$ & $265(60.8 \%)$ & 0.743 \\
\hline Alcohol use & $35(35 \%)$ & $128(29.4 \%)$ & 0.269 \\
\hline Treatment & & & \\
\hline Clip & $42(42 \%)$ & $202(46.3 \%)$ & 0.433 \\
\hline Coil & $52(52 \%)$ & $189(43.3 \%)$ & 0.117 \\
\hline No treatment & $4(4 \%)$ & $40(9.2 \%)$ & 0.08 \\
\hline Anterior circulation & $78(78 \%)$ & $365(83.7 \%)$ & 0.173 \\
\hline Mean aneurysm size (mm) & $7.0 \pm 5.5$ & $7.4 \pm 4.7$ & 0.256 \\
\hline Mean Hunt \& Hess grade & $2.4 \pm 1.3$ & $2.7 \pm 1.4$ & 0.127 \\
\hline Mean WFNS grade & $2.5 \pm 1.5$ & $2.6 \pm 1.6$ & 0.389 \\
\hline Mean Fisher grade & $3.4 \pm 0.6$ & $3.4 \pm 0.7$ & 0.334 \\
\hline Mean GOS score at discharge & $3.3 \pm 1.1$ & $3.2 \pm 1.3$ & 0.668 \\
\hline Hean values are presented as the mean \pm SD. & $31(31 \%)$ & $158(36 \%)$ & 0.323 \\
\hline more than 20 miles underwent both endovascular coiling and surgical clipping.
\end{tabular}

relative equality of severity of presentation across patient groups at the time of admission to the OSH. Furthermore, the need for EVD placement and intubation at Methodist Hospital, as well as GCS score at Methodist Hospital, also failed to reach statistical significance, once more indicating no significant difference in patient characteristics after arrival based on transfer distance.

\section{Mortality Rate as a Function of Transfer Distance}

To delineate the relationship between transfer distance and mortality, the mortality rate for IHT in 20-mile intervals is plotted in Fig. 1. The mortality rate for each 20 - 


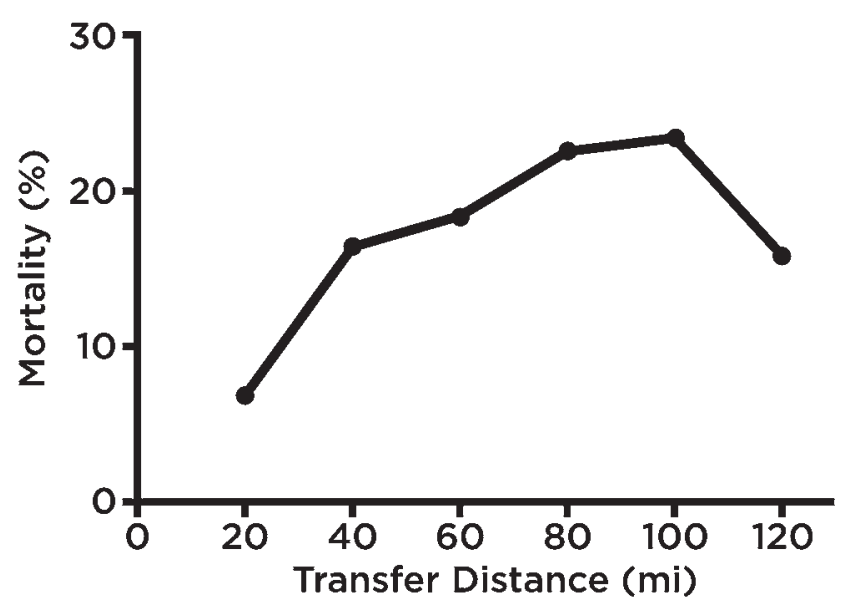

FIG. 1. Mortality rate plotted as a function of distance in miles (mi).

mile interval is defined as the number of deaths in that distance interval divided by the total number of patients transported in that interval. Notably, the mortality rate continued to increase for distances greater than 40 miles and for distances up to 100 miles. The mortality rate declines for distances greater than 100 miles but does not return to the rate seen for transfers of less than 20 miles.

Based on the graph displayed in Fig. 1, the distance groups were dichotomized a second time into patients transferred less than 40 miles $(n=191)$ and patients transferred more than 40 miles $(n=345)$, as this appeared to be a natural cutoff point for differences in mortality. The mortality rates for transfers less than 40 miles and more than 40 miles overall and without intervention are shown in Table 3. The mortality rate for these patients was statistically significant $(p=0.019)$, with a higher mortality rate in patients being transferred from longer distances. The measures of morbidity were similar in terms of the proportion of patients discharged to home and SNF/LTAC, while the rate of discharge to a rehabilitation center was higher for the group undergoing IHT of less than 40 miles. The higher rate of discharge to a rehabilitation center for patients undergoing IHT may be due to the increased survival rate mentioned previously.

\section{Patients Grouped Based on Transfer Method}

Following the analysis of transfer distance, the 536 patients who underwent IHT were dichotomized into groups transferred by ground ambulance $(n=272$; transfer distance $42.8 \pm 36.7$ miles; mean age $55.9 \pm 13.8$ years) and air ambulance $(n=264$; transfer distance $74.3 \pm 51.2$ miles; mean age $55.3 \pm 12.5$ years). Table 4 displays the demographic and outcome findings for the method of transport groupings. Many of the demographic variables for the 2 groups failed to reach statistical significance, including age, sex, prior diagnosis of hypertension, or smoking status. There was a preponderance of alcohol use in the group transferred by air $(\mathrm{p}=0.034)$, and, as expected, the transfer distance was significantly greater for the group transferred by air $(\mathrm{p}=0.001)$.

Many of the aneurysm-related variables were similar across the 2 groups, including location (anterior vs poste-
TABLE 3. Clinical features of patients who underwent IHT of less than versus more than 40 miles

\begin{tabular}{lccc}
\hline Variable & $\begin{array}{c}<40 \text { Miles } \\
(n=191)\end{array}$ & $\begin{array}{c}>40 \text { Miles } \\
(n=345)\end{array}$ & $\begin{array}{c}p \\
\text { Value }\end{array}$ \\
\hline Mortality & $22(11.52 \%)$ & $67(19.4 \%)$ & 0.019 \\
\hline Discharge disposition & & & \\
\hline Rehabilitation & $95(49.7 \%)$ & $141(40.9 \%)$ & 0.048 \\
\hline SNF/LTAC & $12(6.28 \%)$ & $11(3.19 \%)$ & 0.090 \\
\hline Death & $22(11.5 \%)$ & $66(19.1 \%)$ & 0.023 \\
\hline Home & $62(32.5 \%)$ & $127(36.8 \%)$ & 0.313 \\
\hline
\end{tabular}

TABLE 4. Clinical features of patients undergoing IHT based on transfer method

\begin{tabular}{|c|c|c|c|}
\hline Variable & $\begin{array}{l}\text { Ground } \\
(n=272)\end{array}$ & $\begin{array}{c}\text { Air } \\
(n=264)\end{array}$ & $\begin{array}{c}p \\
\text { Value }\end{array}$ \\
\hline Mean transfer distance (miles) & $42.8 \pm 36.7$ & $74.3 \pm 51.2$ & 0.001 \\
\hline Mean age (yrs) & $55.9 \pm 13.8$ & $55.3 \pm 12.5$ & 0.054 \\
\hline Female sex & $197(72.4 \%)$ & $179(67.8 \%)$ & 0.242 \\
\hline Hypertension & $144(52.9 \%)$ & $140(53 \%)$ & 0.597 \\
\hline Smoker & $159(58.5 \%)$ & $165(62.5 \%)$ & 0.338 \\
\hline Alcohol use & $94(34.6 \%)$ & $69(26.1 \%)$ & 0.034 \\
\hline \multicolumn{4}{|l|}{ Treatment* } \\
\hline Clip & $120(44.1 \%)$ & $124(47 \%)$ & 0.507 \\
\hline Coil & $131(48.2 \%)$ & $110(41.7 \%)$ & 0.131 \\
\hline No treatment & $18(6.6 \%)$ & $26(9.8 \%)$ & 0.173 \\
\hline Anterior circulation & $224(82.4 \%)$ & $219(83 \%)$ & 0.854 \\
\hline Mean aneurysm size $(\mathrm{mm})$ & $7.0 \pm 4.6$ & $7.6 \pm 5.1$ & 0.064 \\
\hline $\begin{array}{l}\text { Mean Hunt \& Hess grade at } \\
\text { admission }\end{array}$ & $2.3 \pm 1.3$ & $2.9 \pm 1.4$ & 0.000 \\
\hline Mean WFNS grade & $2.3 \pm 1.6$ & $2.9 \pm 1.6$ & 0.000 \\
\hline Mean Fisher grade & $3.4 \pm 0.7$ & $3.5 \pm 0.6$ & 0.005 \\
\hline Mean GOS score at discharge & $3.3 \pm 1.2$ & $3.1 \pm 1.2$ & 0.021 \\
\hline Intubated prior to arrival to IU & $67(24.6 \%)$ & $100(37.9 \%)$ & 0.001 \\
\hline Intubated after arrival to IU & $13(4.8 \%)$ & $14(5.3 \%)$ & 0.782 \\
\hline EVD at $\mathrm{OSH}$ & $3(1.1 \%)$ & $7(2.7 \%)$ & 0.185 \\
\hline EVD on arrival to IU & $67(24.6 \%)$ & $91(34.5 \%)$ & 0.013 \\
\hline Mean GCS score at OSH & $13.1 \pm 3.7$ & $11.9 \pm 4.5$ & 0.012 \\
\hline Mean GCS score on arrival to IU & $12.1 \pm 4.1$ & $10.6 \pm 4.6$ & 0.000 \\
\hline $\begin{array}{l}\text { Mean admission to treatment time } \\
\text { (hrs) }\end{array}$ & $22.4 \pm 28.3$ & $30.1 \pm 54$ & 0.054 \\
\hline Mean aSAH to treatment time (hrs) & $37.1 \pm 40.4$ & $41.3 \pm 63.3$ & 0.352 \\
\hline Antifibrinolytic & $56(20.6 \%)$ & $56(21.2 \%)$ & 0.859 \\
\hline Rebleeding & $9(3.31 \%)$ & $11(4.17 \%)$ & 0.600 \\
\hline Stroke center & $112(41.2 \%)$ & $99(37.5 \%)$ & 0.421 \\
\hline \multicolumn{4}{|l|}{ Discharge disposition } \\
\hline Rehabilitation & $109(40.1 \%)$ & $127(48.1 \%)$ & 0.061 \\
\hline SNF/LTAC & $14(5.1 \%)$ & $9(3.4 \%)$ & 0.321 \\
\hline Death & $37(13.8 \%)$ & $51(19.3 \%)$ & 0.074 \\
\hline Home & $112(41.2 \%)$ & $77(29.2 \%)$ & 0.004 \\
\hline
\end{tabular}

Mean values are presented as the mean \pm SD.

* Three patients who were transported via ground and 4 patients who were transported via air underwent both endovascular coiling and surgical clipping. 
TABLE 5. Three-way ANOVA analysis for patients who presented directly to Methodist Hospital versus those who underwent IHT of less than 20 or greater than 20 miles

\begin{tabular}{ccccc}
\hline Variable & $\begin{array}{c}\text { No Transfer } \\
(\mathrm{n}=68)\end{array}$ & $\begin{array}{c}<20 \text { Miles } \\
(\mathrm{n}=100)\end{array}$ & $\begin{array}{c}>20 \text { Miles } \\
(\mathrm{n}=436)\end{array}$ & $\begin{array}{c}\mathrm{p} \\
\text { Value }\end{array}$ \\
\hline Mean age (yrs) & $52.3 \pm 11.5$ & $56.6 \pm 12.9$ & $55.4 \pm 13.2$ & 0.102 \\
\hline $\begin{array}{c}\text { Mean aneurysm } \\
\text { size (mm) }\end{array}$ & $6.6 \pm 3.6$ & $7.0 \pm 5.5$ & $7.4 \pm 4.7$ & 0.384 \\
\hline $\begin{array}{c}\text { Mean admission } \\
\text { to treatment } \\
\text { time (hrs) }\end{array}$ & $33.6 \pm 58.1$ & $25.5 \pm 50.4$ & $26.2 \pm 40.5$ & 0.460 \\
\hline $\begin{array}{c}\text { Mean aSAH to } \\
\text { treatment time } \\
\text { (hrs) }\end{array}$ & $29.4 \pm 23.5$ & $40.2 \pm 53.5$ & $38.5 \pm 52.4$ & 0.362 \\
\hline Mortality & $9(13.2 \%)$ & $7(7 \%)$ & $82(18.8 \%)$ & 0.012 \\
\hline No intervention & $4(5.9 \%)$ & $4(4 \%)$ & $40(9.17 \%)$ & 0.181 \\
\hline Intervention & $5(7.4 \%)$ & $3(3 \%)$ & $42(9.63 \%)$ & 0.091 \\
\hline
\end{tabular}

Mean values are presented as the mean \pm SD.

rior circulation) and aneurysm size. The difference in the Fisher grade was statistically significant $(p=0.005)$, with the air transportation cohort having a higher Fisher grade on admission, as were the clinical ratings for aSAH (Hunt and Hess grade $[p=0.000]$ and WFNS grade $[p=0.000])$. The difference in the time of aSAH to intervention did not reach statistical significance. There was an 8-hour increase in duration of time from admission to treatment for the air cohort compared with the ground cohort $(\mathrm{p}=$ $0.054)$. There were no significant differences between the 2 groups as far as initial evaluation at a stroke center or administration of antifibrinolytic therapies. The preoperative rebleeding rates were also similar between the 2 groups.

Further metrics characterizing patients' status at the $\mathrm{OSH}$ and on arrival to the tertiary facility showed a significant difference in the patients' status between the 2 groups. Patients transferred by air were statistically more likely to be intubated prior to arrival $(p=0.001)$, receive an EVD at the tertiary facility $(\mathrm{p}=0.013)$, and demonstrate a lower GCS score at the OSH $(p=0.012)$ and GCS score on arrival $(\mathrm{p}=0.000)$; all of these factors indicated that patients transferred by air ambulance arrived in worse neurological condition than their counterparts transferred by ground.

The GOS score was statistically different, with the cohort transported by ground having a significantly better GOS score at discharge than the group transferred by air $(p=0.021)$. The improved GOS score at discharge resulted in an improved discharge disposition, with a higher proportion of patients transferred by ground being discharged to home $(\mathrm{p}=0.004)$. There was no difference in the likelihood of patients discharged to rehabilitation, SNF/LTAC, or those who died.

\section{Analysis Across All Groups by Distance and Method}

To discern the effect of transport distance, a variation on the 3-way ANOVA test was run for no transfer, transfer less than 20 miles, and transfer more than 20 miles and is shown in Table 5. For all groups, the demographic
TABLE 6. Three-way ANOVA analysis for patients who came directly to Methodist Hospital versus those who underwent ground versus air IHT

\begin{tabular}{lcccc}
\hline \multicolumn{1}{c}{ Variable } & $\begin{array}{c}\text { No Transfer } \\
(\mathrm{n}=68)\end{array}$ & $\begin{array}{c}\text { Ground } \\
(\mathrm{n}=272)\end{array}$ & $\begin{array}{c}\text { Air } \\
(\mathrm{n}=264)\end{array}$ & $\begin{array}{c}\mathrm{p} \\
\text { Value }\end{array}$ \\
\hline Mean age (yrs) & $52.3 \pm 11.5$ & $55.9 \pm 13.8$ & $55.3 \pm 12.5$ & 0.125 \\
\hline $\begin{array}{c}\text { Mean aneurysm size } \\
(\mathrm{mm})\end{array}$ & $6.6 \pm 3.6$ & $7.0 \pm 4.6$ & $7.6 \pm 5.1$ & 0.140 \\
$\begin{array}{c}\text { Mean admission to } \\
\text { treatment time (hrs) }\end{array}$ & $33.6 \pm 58.1$ & $22.4 \pm 28.3$ & $30.1 \pm 54$ & 0.096 \\
\hline $\begin{array}{c}\text { Mean aSAH to treat- } \\
\text { ment time (hrs) }\end{array}$ & $29.4 \pm 23.5$ & $37.1 \pm 40.4$ & $41.3 \pm 63.3$ & 0.232 \\
\hline Mortality & $9(13.2 \%)$ & $38(13.9 \%)$ & $51(19.3 \%)$ & 0.190 \\
\hline No intervention & $4(5.9 \%)$ & $18(6.62 \%)$ & $26(9.85 \%)$ & 0.989 \\
\hline Intervention & $5(7.4 \%)$ & $20(7.35 \%)$ & $25(9.47 \%)$ & 0.999 \\
\hline
\end{tabular}

Mean values are presented as the mean $\pm S D$.

data failed to reach statistical significance in terms of age, aneurysm size, admission to treatment time, and aSAH to treatment time. The outcome of mortality was found to be statistically significant across the groups, with the cohort transported more than 20 miles having an increased rate of mortality compared with the other groups $(\mathrm{p}=0.012)$.

In a similar fashion, the effect of transport method was computed using a variation of the 3-way ANOVA as previously described, and the results are displayed in Table 6 . Again, there was no difference in computed demographic statistics in terms of age, aneurysm size, time from admission to treatment, or time from aSAH to treatment. In addition, there were no statistically significant differences in outcomes for overall mortality, mortality after definitive intervention, or mortality prior to intervention.

\section{Multivariate Analysis}

A multivariate analysis was performed using a logistical regression method to ascertain which of a subset of collected variables (hypertension, aneurysm size, Hunt and Hess grade, WFNS grade, EVD placement, OSH GCS score, and transfer distance more than 20 miles) predicted the outcome of mortality for the transferred patients. First, the regression was computed based on transfer distance, and the results are shown in Table 7. Both Hunt and Hess grade on admission $(p=0.000)$ and a transport distance greater than 20 miles $(\mathrm{p}=0.007)$ predicted mortality with statistical significance. Similarly, a multivariate logistic regression was analyzed for the prediction of mortality in the comparison of ground and air transportation, with the results shown in Table 8. Only the Hunt and Hess grade on admission predicted mortality in a statistically significant manner for these patient cohorts.

\section{Discussion}

The mortality rate for patients initially presenting to an outside hospital and subsequently undergoing IHT to a tertiary aneurysm facility displayed a clear, nonlinear dependence on distance (Fig. 1). Importantly, there was no intuitive direct link between transfer distance and patient 
TABLE 7. Multivariate analysis of transfer distance

\begin{tabular}{lc}
\hline \multicolumn{1}{c}{ Variable } & p Value \\
\hline Hypertension & 0.170 \\
\hline Aneurysm size & 0.108 \\
\hline Admission Hunt \& Hess grade & 0.000 \\
\hline WFNS grade & 0.149 \\
\hline EVD at IU & 0.299 \\
\hline GCS score at OSH & 0.299 \\
\hline >20-mile IHT & 0.007 \\
\hline
\end{tabular}

outcome; however, the distance of IHT should be considered a surrogate for patient transport time and difficulty involving ground or air ambulance transportation. Indeed, the abrupt doubling of the mortality rate at 40 miles, compared with transfers of less than 40 miles, indicates that there is a clinically significant difference between these 2 transfer groups (Fig. 1 and Table 3). Given the number of variables involved in IHT, it is likely that the correlation between mortality rate and IHT distance is multifactorial. However, there were no statistically significant differences in demographics between the groups transported less than 20 miles and those transported more than 20 miles. Moreover, the clinical markers selected to indicate severity of presentation (WFNS grade, Fisher grade, Hunt and Hess grade, EVD, and intubation status) showed the clinical presentation to be quite similar between the groups.

One factor that provides an explanation as to why the group undergoing longer IHT would have a higher mortality rate is that a significantly greater proportion of patients undergoing IHT for shorter distances (i.e., $<20$ miles) were first treated at certified stroke centers $(p=0.000)$. Presumably, initial evaluation and treatment at the hospitals lacking stroke center certification led to inadequate cardiovascular and neurological management after the SAH ictus. Indeed, OSH emergency departments lacking neurosurgical coverage and stroke center designation may not have the necessary experience to provide appropriate measures and orders for the transport team to adequately manage the patient population during IHT.

Furthermore, the clinical assessments and correspondence between an initial hospital evaluation at a designated certified stroke center and the receiving hospital are likely to be more reliable when compared with the hospitals with little experience in managing intracranial hemorrhage, specifically as it relates to aSAH. The identification of significant deterioration was presumably more challenging among patients presenting from non-stroke centers. However, this explanation does not materialize as improved clinical (Hunt and Hess grade, WFNS grade, and GCS score) or radiographic (Fisher grade) findings on admission for the patients traveling less than 20 miles. In addition, the 2 groups showed no difference in their need for advanced procedures (e.g., intubation or EVD placement) at the OSH or on admission to the tertiary hospital. However, as previously mentioned, it is highly likely that hospitals within a 20-mile radius of Methodist Hospital have predetermined and often-used transport protocols that allow for optimal IHT.
TABLE 8. Multivariate analysis of travel method

\begin{tabular}{lc}
\hline \multicolumn{1}{c}{ Variable } & p Value \\
\hline Hypertension & 0.211 \\
\hline Aneurysm size & 0.017 \\
\hline Admission Hunt \& Hess grade & 0.000 \\
\hline WFNS grade & 0.701 \\
\hline EVD at IU & 0.443 \\
\hline GCS score at OSH & 0.408 \\
\hline Method of IHT & 0.585 \\
\hline
\end{tabular}

Many of the variables that were initially hypothesized as being associated with the overall outcomes and mortality of IHT for aSAH patients were found to be statistically unrelated. For example, the difference in intervention times (i.e., timing of onset of aSAH to intervention and admission to intervention) did not explain the difference in outcomes between the groups transferred less than 20 miles and more than 20 miles, as these times were clinically and statistically similar. Analogously, the rebleeding rate was found to be similar between the 2 groups. A multivariate analysis of the transport distance with mortality as the end point found that only the Hunt and Hess grade and a transport distance of more than 20 miles predicted mortality with statistical significance. Thus, it is likely that there are other variables that were not accounted for in the present analysis that led to the higher mortality rate in the group transported more than 20 miles. It is important to note the improvement in mortality rates for patients transported more than 100 miles. Similar results have been found in prior studies. ${ }^{18}$ The most probable explanation of this improved clinical outcome during IHT is that primarily stable patients were selected for transport for these longer distances.

The comparison of patients who underwent IHT to those who presented directly to a tertiary center indicated that there were no significant differences in demographics, severity of presentation, or outcomes when combining all of the transferred patients into one group. This relationship held true whether patients received definitive intervention or not. The effect of transport distance on the rate of mortality was only retained when breaking the group undergoing IHT into the cohorts (i.e., $<20$ miles and > 20 miles) and performing a 3-way ANOVA. The selected demographic information of age, aneurysm size, and treatment times failed to provide an underlying etiology for this outcome. Again, it is likely that the reduced distance and increased familiarity with IHT protocols resulted in patients undergoing IHT less than 20 miles being evaluated and managed at the tertiary hospital in a time frame more similar to that of the group who presented directly to the tertiary center.

The analysis of ground versus air ambulance IHT provides a number of interesting issues for the present study. First, the patients transported via air ambulance had significantly worse Hunt and Hess and WFNS grades at presentation. This is further underscored by the fact that the GCS score on admission to Methodist Hospital was statistically worse for patients transported via air ambulance 
than those transferred via ground (mean 10.6 for air and 12.1 for ground), a difference in score of approximately 1.5 GCS points. This difference in presentation manifested with a significantly higher rate of EVD placement for the group undergoing IHT by air, again, a surrogate for poor clinical presentation. Furthermore, the lower GCS score of the air cohort resulted in a significantly higher rate of intubation at the outside hospitals. Thus, patients who were transported by air either arrived to the outside hospitals with a poor clinical presentation or decompensated prior to or during IHT.

The outcome data for ground versus air transport displayed a clear improvement in GOS score at discharge and in the rate of discharge to home in the cohort that was transported by ground. This is explained by the improved clinical presentation at both the outside hospital and on admission for the group transported by ground. Interestingly, the mortality rate was higher for the air transport group, but this did not reach statistical significance. Furthermore, the difference in mortality rates when comparing ground and air IHT $(\sim 6 \%)$ was significantly smaller than the difference between patients undergoing IHT of less than 20 miles and greater than 20 miles $(\sim 12 \%)$. Thus, there appears to be some improvement in overall mortality rate for patients who are transported by air. This is further underscored by the fact that the transport distance was significantly longer for the air cohort than the ground cohort.

One variable where the transport method would be expected to make a major impact would be the timing of onset of aSAH to intervention and admission to intervention. In both instances, there was a shorter time interval to treatment for ground transport than for air transport (onset aSAH to intervention, $37.1 \pm 40.4$ hours [ground] vs 41.3 \pm 63.3 hours [air]; admission to intervention, $22.4 \pm 28.3$ hours [ground] vs $30.1 \pm 54$ hours [air]). In short, it appears that the patients transported via air ambulance did not receive treatment within a time frame that would make the resource expenditure beneficial when compared with alternative modes of transport. Thus, there is a need to focus on shortening the treatment time after arrival to allow the duration of the transport to become more influential on the final outcome.

It is important to note that this study had a number of limitations. First, it is a retrospective study that evaluates 8 years of clinical data. Inherently, it is not possible to collect data on variables that were not accounted for in the hospital electronic medical record. As such, we were unable to retrieve important variables, such as total transport time, environmental factors affecting transport, or images obtained at the $\mathrm{OSH}$, that would provide a better indication of a patient's neurological status at presentation. Furthermore, there were no records regarding the adequacy of patient management during transport or serial neurological examinations that would indicate a change in clinical status. Thus, the study is limited to assuming that no neurological assessment was performed between the OSH and presentation to the tertiary center, and the finding of clinical deterioration is based on neurological examinations and imaging findings from different practitioners and hospitals, respectively. Unfortunately, it is not possible to account for how each of these variables affected the reported results.

\section{Conclusions}

Aneurysmal SAH remains a challenging neurosurgical disease process that requires highly coordinated care in tertiary referral centers. The time from admission to treatment must continue to improve. In this study, transport distance and transport method appeared to have a significant effect on patient mortality.

\section{References}

1. Biller J, Godersky JC, Adams HP Jr: Management of aneurysmal subarachnoid hemorrhage. Stroke 19:1300-1305, 1988

2. Broderick JP, Brott TG, Duldner JE, Tomsick T, Leach A: Initial and recurrent bleeding are the major causes of death following subarachnoid hemorrhage. Stroke 25:1342-1347, 1994

3. de Rooij NK, Linn FH, van der Plas JA, Algra A, Rinkel GJ: Incidence of subarachnoid haemorrhage: a systematic review with emphasis on region, age, gender and time trends. J Neurol Neurosurg Psychiatry 78:1365-1372, 2007

4. Fujii Y, Takeuchi S, Sasaki O, Minakawa T, Koike T, Tanaka R: Ultra-early rebleeding in spontaneous subarachnoid hemorrhage. J Neurosurg 84:35-42, 1996

5. Germans MR, Coert BA, Vandertop WP, Verbaan D: Time intervals from subarachnoid hemorrhage to rebleed. J Neurol 261:1425-1431, 2014

6. Gooderham PA, Steinberg GK: Reflections on the benefits and pitfalls of ultra-early aneurysm treatment after subarachnoid hemorrhage. World Neurosurg 77:261-262, 2012

7. Holland CM, McClure EW, Howard BM, Samuels OB, Barrow DL: Interhospital transfer of neurosurgical patients to a high-volume tertiary care center: opportunities for improvement. Neurosurgery 77:200-207, 2015

8. Inagawa T: Ultra-early rebleeding within six hours after aneurysmal rupture. Surg Neurol 42:130-134, 1994

9. Inagawa $\mathrm{T}$, Kamiya K, Ogasawara H, Yano T: Rebleeding of ruptured intracranial aneurysms in the acute stage. Surg Neurol 28:93-99, 1987

10. Johnston SC, Selvin S, Gress DR: The burden, trends, and demographics of mortality from subarachnoid hemorrhage. Neurology 50:1413-1418, 1998

11. Kassell NF, Torner JC, Haley EC Jr, Jane JA, Adams HP, Kongable GL: The International Cooperative Study on the Timing of Aneurysm Surgery. Part 1: Overall management results. J Neurosurg 73:18-36, 1990

12. Kassell NF, Torner JC, Jane JA, Haley EC Jr, Adams HP: The International Cooperative Study on the Timing of Aneurysm Surgery. Part 2: Surgical results. J Neurosurg 73:37-47, 1990

13. Laidlaw JD, Siu KH: Ultra-early surgery for aneurysmal subarachnoid hemorrhage: outcomes for a consecutive series of 391 patients not selected by grade or age. J Neurosurg 97:250-258, 247-249, 2002

14. Lovelock CE, Rinkel GJ, Rothwell PM: Time trends in outcome of subarachnoid hemorrhage: Population-based study and systematic review. Neurology 74:1494-1501, 2010

15. Naidech AM, Janjua N, Kreiter KT, Ostapkovich ND, Fitzsimmons BF, Parra A, et al: Predictors and impact of aneurysm rebleeding after subarachnoid hemorrhage. Arch Neurol 62:410-416, 2005

16. Naval NS, Chang T, Caserta F, Kowalski RG, Carhuapoma JR, Tamargo RJ: Impact of pattern of admission on outcomes after aneurysmal subarachnoid hemorrhage. J Crit Care 27:532.e1-532.e7, 2012 
17. Nuño M, Patil CG, Lyden P, Drazin D: The effect of transfer and hospital volume in subarachnoid hemorrhage patients. Neurocrit Care 17:312-323, 2012

18. O'Kelly CJ, Spears J, Urbach D, Wallace MC: Proximity to the treating centre and outcomes following subarachnoid hemorrhage. Can J Neurol Sci 38:36-40, 2011

19. Park J, Woo H, Kang DH, Kim YS, Kim MY, Shin IH, et al: Formal protocol for emergency treatment of ruptured intracranial aneurysms to reduce in-hospital rebleeding and improve clinical outcomes. J Neurosurg 122:383-391, 2015

20. Robbert M, Hoogmoed J, van Straaten HA, Coert BA, Peter Vandertop W, Verbaan D: Time intervals from aneurysmal subarachnoid hemorrhage to treatment and factors contributing to delay. J Neurol 261:473-479, 2014 (Erratum in J Neurol 261:1850, 2014)

21. Roos YB, Beenen LF, Groen RJ, Albrecht KW, Vermeulen M: Timing of surgery in patients with aneurysmal subarachnoid haemorrhage: rebleeding is still the major cause of poor outcome in neurosurgical units that aim at early surgery. $\mathbf{J}$ Neurol Neurosurg Psychiatry 63:490-493, 1997

22. Sakaki T, Morimoto T, Hoshida T, Kawaguchi S, Nakase H, Fukuzumi A: Rebleeding during transport of patients with a ruptured intracranial aneurysm. J Stroke Cerebrovasc Dis 8:38-41, 1999

23. Schievink WI: Intracranial aneurysms. N Engl J Med 336:28-40, 1997

24. Suarez JI, Tarr RW, Selman WR: Aneurysmal subarachnoid hemorrhage. N Engl J Med 354:387-396, 2006

25. Svenson JE, O'Connor JE, Lindsay MB: Is air transport faster? A comparison of air versus ground transport times for interfacility transfers in a regional referral system. Air Med J 25:170-172, 2006

26. van Gijn J, Kerr RS, Rinkel GJ: Subarachnoid haemorrhage. Lancet 369:306-318, 2007

27. Wagner J, Iwashyna TJ, Kahn JM: Reasons underlying inter- hospital transfers to an academic medical intensive care unit. J Crit Care 28:202-208, 2013

28. Walcott BP, Coumans JV, Mian MK, Nahed BV, Kahle KT: Interfacility helicopter ambulance transport of neurosurgical patients: observations, utilization, and outcomes from a quaternary level care hospital. PLoS One 6:e26216, 2011

\section{Disclosures}

The authors report no conflict of interest concerning the materials or methods used in this study or the findings specified in this paper.

\section{Author Contributions}

Conception and design: Weyhenmeyer, Guandique. Acquisition of data: Weyhenmeyer, Guandique, Leibold, Lehnert, Parish, Han, Tuchek, Payner. Analysis and interpretation of data: all authors. Drafting the article: Cohen-Gadol, Weyhenmeyer, Guandique, Lehnert, Parish, Han, Tuchek, Payner. Critically revising the article: Cohen-Gadol, Weyhenmeyer, Guandique, Parish, Han, Tuchek, Pandya, Leipzig, DeNardo, Scott. Reviewed submitted version of manuscript: Cohen-Gadol, Weyhenmeyer, Leibold, Lehnert, Parish, Han, Tuchek, Pandya, Leipzig, Payner, DeNardo, Scott. Approved the final version of the manuscript on behalf of all authors: Cohen-Gadol. Statistical analysis: Cohen-Gadol, Weyhenmeyer, Pandya. Administrative/technical/material support: Cohen-Gadol, Weyhenmeyer. Study supervision: Cohen-Gadol, Weyhenmeyer, Pandya, Leipzig, Payner, DeNardo, Scott.

\section{Correspondence}

Aaron A. Cohen-Gadol, Goodman Campbell Brain and Spine, Indiana University Department of Neurological Surgery, 355 W 16th St., Ste. \#5100, Indianapolis, IN 46202. email: acohenmd@ gmail.com. 